\title{
O terapeuta ocupacional como consultor na adequação do layout de uma biblioteca universitária ${ }^{1}$
}

\author{
Iranise Moro Pereira Jorge, Aline Andreia Klein, Aline dos Santos Ávila, \\ Ellen Geraldine Sakowicz
}

Departamento de Terapia Ocupacional, Universidade Federal do Paraná - UFPR, Curitiba, PR, Brasil.

\begin{abstract}
Resumo: Objetivo: O presente artigo tem como objetivo apresentar o diagnóstico, a elaboração e o planejamento do layout da biblioteca do campus Rebouças da Universidade Federal do Paraná - UFPR, localizado na cidade de Curitiba-PR. Método: Para a efetivação deste estudo, adotou-se a abordagem metodológica qualitativa e de caráter descritivo exploratório. Inicialmente, foi realizada a análise físico-ambiental, tendo como parâmetros os princípios norteadores da Ergonomia (NR 17) e da Acessibilidade (NBR 9050). Logo após, aconteceu o diagnóstico a partir das observações efetuadas na planta da biblioteca, dos registros feitos com auxílio da máquina fotográfica e de medições com a trena. Resultados: Com base nos resultados da análise do ambiente da biblioteca, verificou-se a necessidade de adequações, pois os ambientes analisados não contemplavam os princípios norteadores do referencial teórico utilizado. Deste modo, para que as intervenções propostas pelas pesquisadoras fossem implementadas, houve o auxílio do Setor de Engenharia, Manutenção e Marcenaria da Universidade, a fim de tornar este ambiente acessível e adequado aos futuros usuários e servidores da biblioteca. Conclusão: Ressaltando-se que a possibilidade de poder adequar o ambiente antes do seu funcionamento favorece um espaço laboral propício ao desenvolvimento das tarefas e da organização do trabalho, e a manutenção da saúde dos usuários, o que contribuirá para um desempenho ocupacional satisfatório, ao utilizar este ambiente.
\end{abstract}

Palavras-chave: Terapia Ocupacional, Biblioteca Universitária, Ergonomia, Acessibilidade.

\section{The occupational therapist as a consultant on a university library layout adequacy}

Abstract: Objective: This article aims to present the diagnosis, development and planning of the Universidade Federal do Paraná library layout - UFPR campus of Rebouças, located in the city of Curitiba. Method: We adopted a methodological approach of qualitative nature and exploratory descriptive character using, initially, the physical-environmental analysis with Ergonomics (NR 17) and Accessibility (NBR 9050) guiding principles. The library diagnosis was then performed using data collected through observations in the library plant, photo camera records and measurements taken with a measuring tape. Results: Based on the results from the library environment analysis, it was verified the need for adjustments as the evaluated environments did not meet the reference guidelines used. Thus, in order to implement the interventions proposed by the researchers, the University Engineering, Maintenance and Joinery department helped to make this environment accessible and appropriate to future users and library workers. Conclusion: The study highlights that the possibility environment adapting before the operation favors a work space adequate to the development of the tasks, a work organization and maintenance of the users' health, which will contribute to a satisfactory occupational performance when using this environment.

Keywords: Occupational Therapy, University Library, Ergonomics, Accessibility.

Autor para correspondência: Iranise Moro Pereira Jorge, Universidade Federal do Paraná, Campus Botânico, Bloco Didático II, Avenida Lothário Meissner, 632, CEP 80210-170, Jardim Botânico, Curitiba, PR, Brasil, e-mail: iranise@ufpr.br

Recebido em Jul. 17, 2015; $1^{\circ}$ Revisão em Out. 16, 2015; $2^{\circ}$ Revisão em Dez. 20, 2015; $3^{\circ}$ Revisão em 12 Jan. 2016 ; Aceito em Fev. 18, 2016 


\section{Introdução}

O presente artigo visa a apresentar o diagnóstico, a análise e a intervenção do layout da Biblioteca do campus Rebouças, com a finalidade de adequar este espaço, tanto para o servidor quanto ao usuário deste ambiente, assim como mostrar o papel do terapeuta ocupacional como consultor neste processo. Ao tornar o ambiente inclusivo, se favorece, desta maneira, o desempenho ocupacional satisfatório para aqueles que o frequentam.

O Sistema de Bibliotecas (SIBI) da Universidade Federal do Paraná (UFPR) é constituído por 20 bibliotecas, sendo uma delas a sede administrativa (Biblioteca Central). Destas, 16 estão distribuídas no município de Curitiba e outras quatro nos municípios de Palotina, Jandaia do Sul, Matinhos e Pontal do Paraná. A biblioteca-alvo deste estudo é a do campus Rebouças, localizada na capital do Paraná.

A palavra "Biblioteca" tem sua origem no termo grego bibliotheké, significando "o lugar onde se guardam livros". Com o desenvolvimento da civilização, sua função e atribuiçốes modificaram-se; atualmente, além de depositária de livros e documentos, passa a ser um lugar de difusáo do conhecimento, assim como um ponto de acesso a fontes de informaçáo (FLECK, 2004). Atualmente, são caracterizadas pela sua função e serviço que oferece, pelo público destinado e pelo seu vínculo institucional. Existem basicamente seis tipos de bibliotecas: as nacionais, as escolares, infantil, universitárias, públicas e especializadas (FUNDAÇÃO..., 2000).

Este estudo teve como enfoque uma biblioteca universitária, que é considerada parte integrante de uma instituição de ensino superior e que possui, como objetivos, apoiar e auxiliar nas atividades acadêmicas voltadas ao ensino e à pesquisa, com vistas a atender os discentes, docentes e funcionários da universidade (PIMENTEL; BERNARDES; SANTANA, 2007; FUNDAÇÃO..., 2000).

$\mathrm{O}$ ambiente da biblioteca, como em qualquer local de trabalho e estudo, deve apresentar boas condiçóes, para que tanto o trabalhador quanto aqueles que o frequentam possam se sentir aptos a desempenhar suas atividades.

Segundo Costa (2008) e Silva (2008), o estudo e arranjo físico de mobiliário e equipamentos em qualquer local de trabalho ou de estudo são visivelmente importantes, pois disso dependem o bem-estar e o bom rendimento daqueles que o frequentam, levando sempre em consideração fatores ecológicos, como ruído, cores e iluminação.
O processo de intervençáo do terapeuta ocupacional na Saúde do Trabalhador envolve três enfoques centrais: a prevenção, a promoçáo e a reabilitaçáo (RODRIGUES; SIMONELLI; LIMA, 2013). A sua atuação possui, como ator central, o trabalhador, analisando a relaçáo que este possui com o trabalho, observando assim as dificuldades deste ambiente e quais são os limites do trabalhador, utilizando como recurso a análise da atividade laboral (WATANABE; GONÇALVES, 2004).

A Consultoria é compreendida como a prestação de serviços realizada por um profissional qualificado, o qual recebe remuneração por seus serviços prestados a um determinado cliente. Possui como objetivo melhorar o desempenho de uma organização empresarial através da transferência de seus conhecimentos e do desenvolvimento de habilidades e atitudes da empresa em que está realizando a consultoria (BLOCK, 1991). Empresas preferem a contratação de consultores devido ao seu caráter de ação imediata, em curto período de tempo, mas de forma adaptada às exigências da empresa (GUÉRIN et al., 2001).

O Terapeuta Ocupacional está habilitado para atuar como consultor, sendo que a sua açáo consiste em ser uma atividade profissional que visa ao diagnóstico e à formulação de soluçóes, sendo relatado por Watanabe e Nicolau (2001) uma das novas possibilidades de atuação deste. Vale destacar que os professores integrantes da LABRAT (Laboratório de Reabilitação, Acessibilidade e Trabalho) do Departamento de Terapia Ocupacional, ao qual o estudo está vinculado, estáo aptos a realizar o trabalho de consultores. O processo de consultoria no estudo em questáo se concretizou pela busca da bibliotecária-chefe da biblioteca do campus Rebouças da UFPR ao LABRAT, do Departamento de Terapia Ocupacional no qual se firmou a parceria.

Para que se possa adequar este espaço, faz-se necessária a realização do diagnóstico referente ao mesmo, baseando-se no estudo da Norma Regulamentadora - NR 17 (ASSOCIAÇÃO..., 1990) e da Norma da Associação Brasileira de Normas Técnicas - NBR 9050 (ASSOCIAÇÃO..., 2004), as quais darão suporte à intervenção.

Por meio da publicação da NR 17 - Ergonomia, do Ministério do Trabalho e Emprego, fica estabelecida uma normatizaçáo para questóes ergonômicas no Brasil. Seu objetivo, conforme a seção 17.1, é o estabelecimento de um conjunto de especificaçôes para adaptar as condiçóes de trabalho às características psicológicas e físicas do profissional, através da definição de diretrizes para a adaptaçáo das condiçôes de trabalho levando-se em conta o conforto e a segurança (BRASIL, 1990). 
A Ergonomia trata-se de uma disciplina que possui como objetivo compreender e modificar as relaçóes da pessoa com o trabalho, através de adaptaçóes e dos limites do trabalhador (CAMAROTTO; SIMONELLI; RODRIGUES, 2013). Conforme Abrahão et al. (2009, p. 19): “[...] bem-estar deveria ser o objetivo maior da produção, uma vez que um dado trabalho pode adaptar-se ao ser humano". Para que uma adequação ergonômica seja eficiente, esta deve ser realizada tanto com o trabalhador quanto com a tarefa que este deve realizar em mente (ADEYEMI, 2010; ROONEY, 1994).

A Terapia Ocupacional tem como missão a investigação das atividades laborais, visando à melhoria das condiçóes e do ambiente de trabalho, assim como o "[...] envolvimento, compreensão e comprometimento dos funcionários na interdependência do processo produtivo [...]" (WATANABE; NICOLAU, 2001, p. 161), possibilitando a elaboração da identidade profissional do sujeito, não se esquecendo da manutenção e adaptação de mobiliários, equipamentos, ferramentas e layout, utilizando-se os preceitos que regem a Ergonomia.

A Análise do Layout, um dos conceitos utilizados pela Ergonomia, tem, por definição, segundo Davok, Pereira e Ordovás (2011, p. 346), como sendo

[...] a disposição física de materiais, móveis e equipamentos em um ambiente, de forma a facilitar e aperfeiçoar os fluxos existentes nesse ambiente, racionalizando o aproveitamento dos espaços e dos recursos materiais disponíveis.

Possui, como objetivo, proporcionar conforto, produtividade, prevenção de acidentes e promoçáo de espaços adequados para a prestação de um serviço, sendo que, para tanto, são feitos estudos com relação a esse ambiente, objetos e mobília que serão usados ali. Ressalta-se que é essencial a implantação e manutenção destas propostas, objetivando proporcionar qualidade de trabalho, desempenho e satisfação do trabalhador (PICOLLI; CARNEIRO; BRASIL, 2000; RIO; PIRES, 2001).

Em uma biblioteca, algumas necessidades devem ser observadas, como o espaço, que permita que com o tempo e com o tamanho do acervo, esta possa se expandir; a iluminação, que é importante para os locais de leitura, devendo estar instalada de forma que não atrapalhe o usuário, bem como a temperatura do ambiente de ser controlada para a preservaçáo dos livros do acervo e proporcionar o bem-estar daqueles que frequentam este local. E, por fim, um ambiente adequado para a leitura, com mesas e cadeiras reguláveis, o que seria o ideal, conforme afirma Chandra et al. (2009).

A Norma Brasileira Regulamentadora (NBR) 9050, da Associação Brasileira de Normas Técnicas (2004, p. 2), que foi validada em 30 de junho de 2004, define acessibilidade como a

[...] possibilidade e condição de alcance, percepçáo e entendimento para a utilizaçáo com segurança e autonomia de edificaçóes, espaço, mobiliário, equipamento urbano e elementos [...].

Discorre também sobre as definiçóes que devem ser destacadas para um entendimento mais amplo de como adequar um ambiente, sendo estas:

$\checkmark$ Acessível: um ambiente acessível é quando este se ajusta para que o indivíduo possa utilizá-lo de forma autônoma, visando à segurança e à comodidade;

$\checkmark$ Praticável: um ambiente praticável é aquele que náo se ajustou a todas as normas da acessibilidade proposta pela ABNT NBR 9050, mas, mesmo assim, permite que os indivíduos o utilizem de forma autônoma;

$\checkmark$ Adaptável: ambiente adaptável é aquele que, com algumas modificaçóes, o ambiente pode ser usado, mas não se encontra ideal. E ambiente não acessível é aquele que não possui o que é necessário para a acessibilidade (PUPO; MELO; FERRÉS, 2008; ASSOCIAÇĀO..., 2004);

$\checkmark$ Adequado:

Ambiente adequado é compreendido como sendo o espaço, a edificação, o mobiliário, o equipamento urbano ou o elemento cujas características foram originalmente planejadas para serem acessíveis (ASSOCIAÇÂO..., 2004, p. 2).

Para organizar o ambiente da biblioteca, é necessário o foco no aspecto físico, que está ligado ao espaço, ao acervo e ao layout, no aspecto técnico e no aspecto administrativo (COSTA, 2008).

\section{Método}

Este trabalho faz parte do programa de Iniciação Científica das pesquisadoras intitulado como "Açóes da Terapia Ocupacional na elaboração e planejamento do layout da biblioteca do campus 
Rebouças da UFPR 2", vinculado ao Laboratório de Reabilitação, Acessibilidade e Trabalho (LABRAT) do Departamento de Terapia Ocupacional da mesma universidade.

A metodologia utilizada nesta pesquisa é uma abordagem metodológica de cunho qualitativo e de caráter descritivo exploratório.

A pesquisa foi estruturada em três etapas, sendo a Primeira etapa, a análise físico-ambiental, a qual foi realizada através de análise da planta baixa, visitas sistematizadas previamente agendadas ao local e coleta de dados (fotos e medidas). Inicialmente, a pesquisa foi orientada pelas medidas de largura e comprimento das salas apresentadas na planta baixa; posteriormente, foram realizadas avaliaçóes in loco para a efetivação destas medidas e dos móveis disponíveis, sendo efetuadas com o auxílio da trena. Também foram fotografados estes ambientes para auxiliar no momento de análise posterior. As imagens obtidas são dos móveis, de vários ângulos, como: de frente, de cima e de lado, assim como do ambiente das salas, dando ênfase aos objetos que estavam nos locais, nos equipamentos e nas portas, janelas e tomadas. No que se refere às fotografias tiradas pelas pesquisadoras, as mesmas serviram como um comparativo entre o antes e o depois das intervençóes. Já no que tange às mediçóes, foram realizadas para apropriar-se da área destinada à biblioteca e do mobiliário existente, para a realização das próximas etapas do estudo. Esta etapa ocorreu no período de agosto de 2014 a setembro de 2014.

A Segunda etapa consistiu no diagnóstico da biblioteca, através dos dados coletados na primeira etapa, comparando estes com o referencial teórico utilizado. Ocorreu no período de setembro de 2014 a novembro de 2014.

O Diagnóstico Ergonômico de um ambiente preza pela relação entre o exercício da atividade e os resultados dessa atividade, e visa à elaboraçáo de uma solução para os problemas encontrados no local analisado (GUÉRIN et al., 2001).

A Terceira etapa foi a execução das adequaçôes ergonômicas e da acessibilidade, assim como da reestruturação do balcão da recepção da biblioteca, que se encontra no primeiro andar da mesma, além de adaptaçóes das estantes do acervo e bancadas de estudo coletivo e individual - todas estas situadas no segundo andar da biblioteca -, também levando-se em conta princípios da Ergonomia e da NBR 9050. É importante ressaltar que as modificaçôes foram realizadas em trabalho conjunto com o Setor de Marcenaria da universidade. Não foi possível cumprir os ajustes planejados no que tange aos postos de trabalho devido à náo previsão de inauguração da biblioteca. Esta etapa foi realizada no período de dezembro de 2014 a junho de 2015.

\section{Resultados e Discussão}

A seguir, serão apresentados os critérios de acessibilidade expostos pela NBR 9050 e pela NR 17, no que se refere à ergonomia, comparando-se com o que foi observado no ambiente da biblioteca e destacando os métodos de intervenção utilizados para modificar o layout, a fim de contemplar um desempenho ocupacional satisfatório àqueles que irão utilizar a biblioteca.

\subsection{Apresentação e análise do ambiente}

A biblioteca ocupa dois andares (Figura 1) de um prédio com três andares. No primeiro andar, encontram-se o balcáo de recepção/devolução/ empréstimo, os escaninhos, a bancada para o computador, o espaço destinado a exposiçóes e as salas da bibliotecária-chefe e demais servidores. No segundo andar, há ambientes para estudo individual e coletivo, acervo, banheiros, copa e posto de trabalho dos servidores. As especialidades do acervo desta biblioteca são referentes aos cursos de Pedagogia, Psicologia, Turismo e, futuramente, Biblioteconomia e Arqueologia. Estima-se atender diretamente cerca de 184 docentes e 2.341 discentes, além dos funcionários técnico-administrativos e da comunidade externa.

Com base na planta baixa da biblioteca, nas visitas in loco e correlacionando com a teoria estudada, foi possível realizar as seguintes intervençôes.

\subsection{Balcão de recepção}

O Balcão de Recepção da Biblioteca do campus Rebouças está situado no primeiro andar da biblioteca, o qual contará, no futuro, com o posto de trabalho dos servidores, podendo ser ocupado por até quatro trabalhadores. Possui como função o empréstimo e a devolução de chaves, o empréstimo de livros e a devolução de livros, e a orientação aos usuários. Este balcão é constituído por uma estrutura em madeira com tampo e laterais em mármore, com dois lados interligados através de uma borda em formato arredondado, possuindo uma altura de 84 centímetros de altura.

Através da análise realizada por observação, medições e referencial teórico, verificou-se a necessidade de 

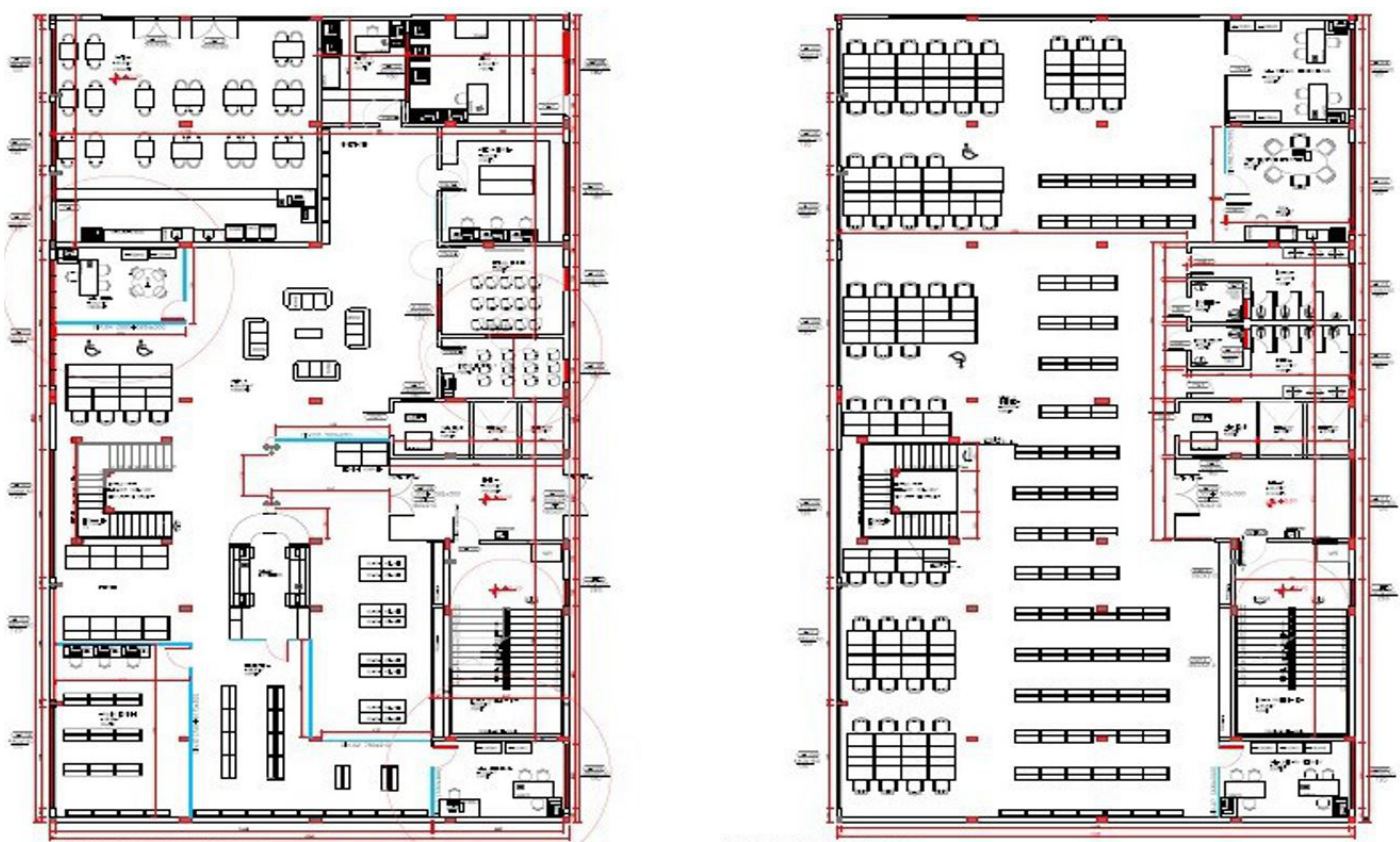

Figura 1. Planta da Biblioteca do campus Rebouças - UFPR. Fonte: Prefeitura de Engenharia da UFPR.

alterar o layout. Estudo apontado por Capri, Bahia e Pinto (2012) demonstra que uma das solicitaçôes apontadas em sua pesquisa foi a modificação da mobília do balcão de atendimento.

$\mathrm{Na}$ primeira visita realizada à biblioteca, foram perceptíveis algumas inadequações, como a instalação das gavetas abaixo do local destinado para o uso de computadores, o que impede o sujeito de ter espaço para acomodar os membros inferiores, e a sua permanência em uma posição neutra; assim, consequentemente, o sujeito não consegue manter uma posição confortável na utilização do posto de trabalho, o que pode causar prejuízos à saúde dos servidores/estagiários que estão expostos a essa situação diariamente (Figura 2). Tal observação foi feita pelas pesquisadoras e pode ser comparada com as observaçóes relatadas na pesquisa de Barreto e Coutinho, no ano de 2012, em uma biblioteca pública do Estado da Bahia, na qual os mesmos encontraram inadequações no balcão de atendimento. Estas descumpriam as medidas propostas pela NBR9050, tornando-se uma barreira arquitetônica para o desempenho laboral satisfatório do trabalhador que iria ocupar este posto de trabalho.

Outro comparativo que pode ser feito com a pesquisa em questão é a do Projeto de Guichê de Atendimento, contextualizado pela Análise Ergonômica do Trabalho e concebido por Fontes et al. (2006), que propuseram um balcão novo, a partir da avaliação do balcão existente.

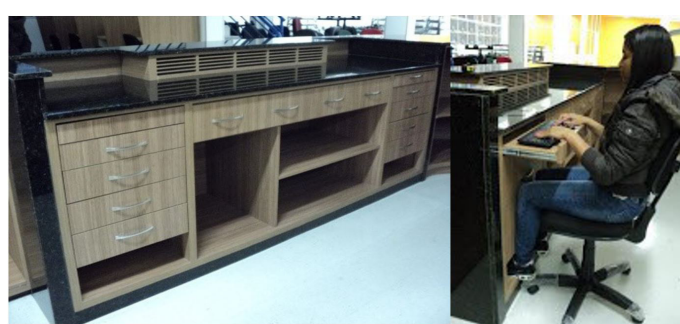

Figura 2. Vista interna do balcão de recepção/ empréstimo/devolução. Fonte: As autoras (2015).

Na seção 17.3 da NR 17, são apresentadas algumas características referentes ao mobiliário, sendo este concebido com regulagens que permitam adaptá-lo às características antropométricas do trabalhador, objetivando alternância de posturas e área de trabalho de fácil alcance, e que possibilite uma boa visualização do trabalhador. É possível destacar que o mobiliário deve ser adaptado não somente às características do corpo humano, mas também ser condizente com as atividades que serão exercidas neste posto de trabalho (BRASIL, 1990) e proporcionar ao trabalhador condiçóes para adoção de uma boa postura, a fim de melhorar seu desempenho laboral e a sua produtividade (MACIEL; MARZIALE, 1997).

Na NBR 9050 de 2004, são expostas algumas medidas adequadas para o ambiente que a pessoa com deficiência física irá utilizar. Para o atendimento de uma pessoa cadeirante, com estatura baixa 
e portador de nanismo, em um local onde haja balcão ou alguma superfície que separe o atendente do atendido, o item 9.5.2.2 determina que, para a aproximação frontal ao balcão, este deve possuir 73 centímetros de altura em relação ao piso, largura de 80 centímetros e uma profundidade de 30 centímetros, para que possa haver a entrada da cadeira na parte inferior do balcão, conforme demonstra a Figura 3 (ASSOCIAÇÃO..., 2004).

Após a realização de uma reunião com a Chefe da Biblioteca do campus Rebouças, com os servidores do Setor de Manutenção, com a Engenharia da Universidade Federal do Paraná e com um servidor de uma das bibliotecas da universidade, para averiguar quais as necessidades do balcáo e quais as modificaçóes que poderiam ser realizadas sem prejudicar a estrutura do móvel e utilizando-se as normas de acessibilidade e dos preceitos da ergonomia, foi esboçado um croqui (Figura 4), o qual é constituído pelas medidas adequadas para que o desempenho ocupacional dos servidores esteja adequado às tarefas que necessitam realizar neste posto de trabalho, sem causar prejuízo à sua saúde. Este croqui foi aprovado pela bibliotecária-chefe e, posteriormente, foram executadas as modificaçôes pelo setor de marcenaria da própria universidade.

Assim, a altura então atual de $84 \mathrm{~cm}$ do balcáo foi mantida, visto que é estabelecida pela NBR 9050 uma altura de $73 \mathrm{~cm}$ a $90 \mathrm{~cm}$ de altura para o mobiliário, possibilitando, com isso, a utilização do balcão tanto na postura sentada, como em pé, permitindo, desta maneira, a manutenção de um

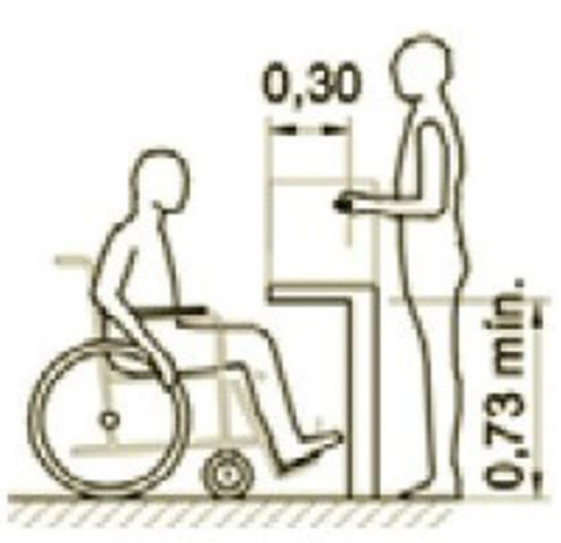

Vista lateral

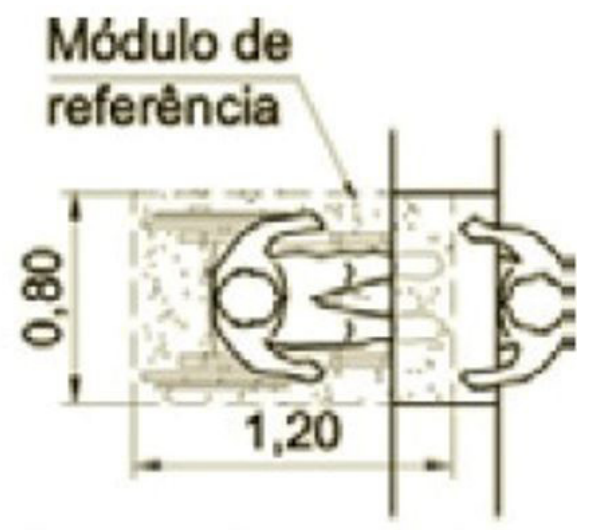

Vista superior

Figura 3. Altura e profundidade do balcão. Fonte: NBR 9050 (ASSOCIAÇÃO..., 2004, p. 93).

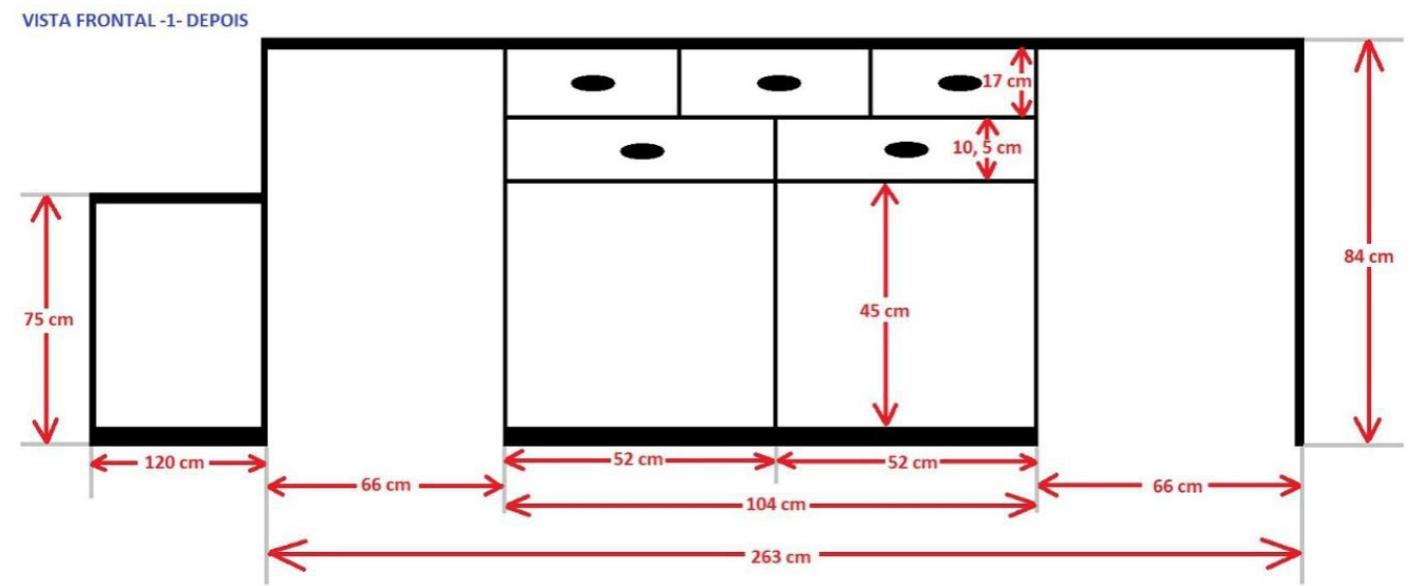

Figura 4. Modelo adequado do balcão. Fonte: As autoras (2015). 
trabalho dinâmico, com mudança frequente de posição (ASSOCIAÇÃO..., 2004).

Em relação às gavetas, indicou-se a sua retirada do local em que se encontravam e sua realocação no espaço disponível no meio do balcão, pois, deste modo, haveria uma espaço adequado para acomodar os membros inferiores no ambiente destinado ao posto de trabalho com o uso de computador. Também foi solicitada a retirada do rodapé, o que impedia que a cadeira se situasse abaixo do balcão (Figura 5).

$\mathrm{Na}$ extremidade esquerda do balcão, foi sugerido que esse espaço possuísse uma altura de $75 \mathrm{~cm}$, com largura de $1,28 \mathrm{~m}$, conforme as normas de acessibilidade, já que esse espaço será destinado ao atendimento ao cadeirante, pessoa com pequena estatura e portador de nanismo (ASSOCIAÇĀO..., 2004) (Figura 6).

\subsection{Guarda-volumes/escaninhos}

Após visita das pesquisadoras à biblioteca universitária, foi possível verificar que a disposição dos guarda-volumes/escaninhos não facilitava o fluxo de pessoas e estes não estavam isolados do restante do ambiente da biblioteca (Figura 7).

Para facilitar o fluxo dos usuários deste ambiente, recomenda-se a distância de $1,30 \mathrm{~m}$ a $1,50 \mathrm{~m}$ entre cada escaninho, pois se considera que a pessoa que está utilizando o guarda-volumes ocupa o mesmo espaço de uma pessoa que se encontra sentada à frente de um computador (ASSOCIAÇÃO..., 2004). Para o cumprimento das medidas expostas pela NBR 9050, foram dadas orientaçóes para a equipe de manutenção da universidade. Também foi constatada, pelas pesquisadoras, a necessidade de se colocar uma parede de acrílico atrás do guarda-volumes, a fim de isolar o espaço destinado aos guarda-volumes do restante da biblioteca (Figura 8).

\subsection{Bancada destinada ao computador}

Durante a visita das pesquisadoras, averiguou-se que a altura do suporte do monitor estava inadequada (Figura 9). Vale ressaltar que a zona de conforto visual é alcançada com a cabeça e o pescoço na vertical, portanto em posição neutra; notou-se que a borda superior da tela encontrava-se na linha horizontal dos olhos. O monitor deve estar posicionado perpendicularmente a janela, para que assim seja evitado o ofuscamento ocasionado pela claridade excessiva e pela luz do sol; a distância confortável olho-tela é de 60-70 cm, ou seja, equivalente ao comprimento do braço, sendo possível enxergar nitidamente letra e detalhes de imagens (BRANDIMILLER, 2002).
Para cumprir o referencial teórico exposto acima, foi solicitado, ao Setor de Marcenaria da universidade, diminuir as medidas do suporte para o monitor - que inicialmente possuía $13 \mathrm{~cm}$ de altura - para $6 \mathrm{~cm}$

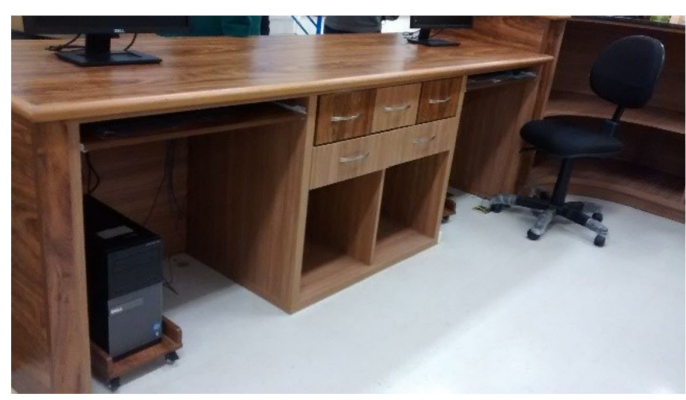

Figura 5. Balcão com as novas alterações. Fonte: As autoras (2015).

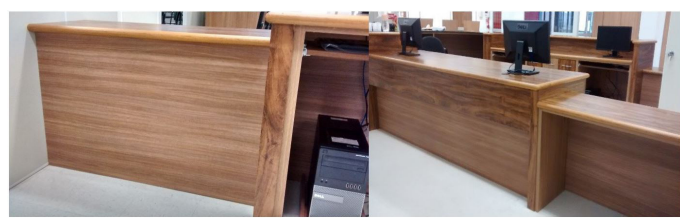

Figura 6. Vista interna e externa da adequação da extremidade esquerda do balcão. Fonte: As autoras (2015).

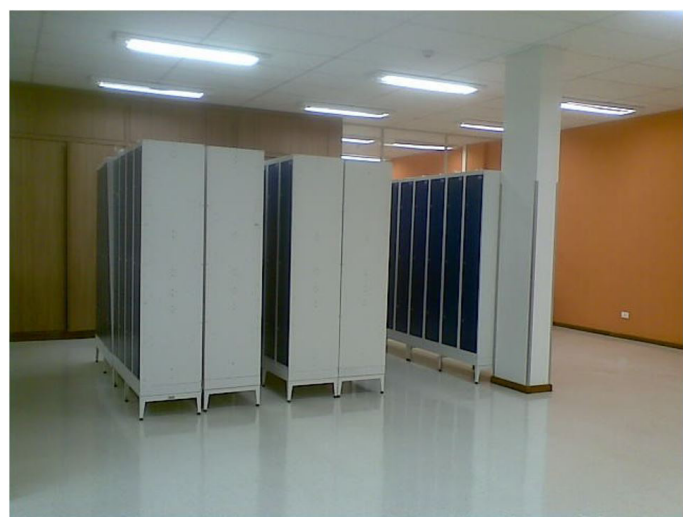

Figura 7. Disposição dos escaninhos antes da intervenção. Fonte: As autoras (2015).

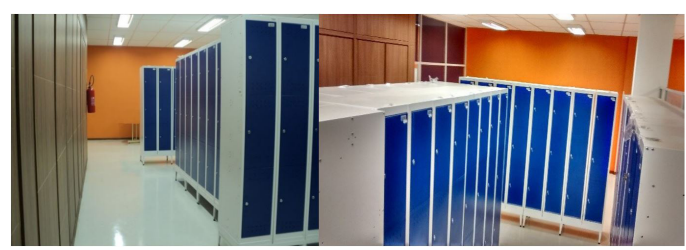

Figura 8. Escaninhos - falta de isolamento com o restante da biblioteca. Fonte: As autoras (2014). 
de altura, com o intuito de o teclado ser alocado abaixo dessa estrutura.

Rooney (1994) cita, em seu estudo, que as cadeiras e os monitores de um computador devem possuir ajustes de altura, sendo importante ressaltar a relaçáo entre a altura da mesa e a altura da cadeira. Moura et al. (2005), em sua pesquisa com locais de trabalho informatizados, demonstram a importância da ergonomia no uso de computadores, pois exposiçôes contínuas a um ambiente estressante e inadequado para si podem causar lesôes em músculos, tendóes e ligamentos, podendo levar à LER (Lesão por Esforços Repetitivos) ou à DORT (Distúrbios Osteomusculares relacionados ao trabalho).

Em um estudo realizado em 2014, na cidade de Setúbal, por Sobral e Lima, com 104 funcionários de uma empresa que fazem o uso rotineiro de computador, foi possível observar que $66 \%$ utilizam de 5 a 6 horas por dia o computador, sendo que a maioria considera que as situaçôes de trabalho não estão adequadas, pois monitores e cadeiras não são ajustáveis. Na Biblioteca do Rebouças, a situaçáo não é a mesma, pois as cadeiras são ajustáveis e a altura do mobiliário que suporta o monitor foi diminuída para possibilitar que todos possam utilizar o computador e se organizar conforme a sua necessidade.

\subsection{Estantes destinadas ao acervo}

Após análise da planta baixa, visitas e observaçôes do ambiente, foi definido que as estantes estariam dispostas paralelamente às luminárias, pois, desta forma, cumpre-se o advertido nos itens 17.5.3.2 e 17.6.3.1 da NR 17: a iluminação deverá ser uniformemente distribuída, a fim de evitar ofuscamento, reflexos, sombras e contrastes excessivos, proporcionando assim maior conforto aos usuários da biblioteca (BRASIL, 1990).

Pensando na acessibilidade dos usuários de portadores de deficiência física, as estantes foram organizadas com o espaço entre elas de, no mínimo, 90 centímetros, e, no máximo, 1,20 m, conforme a norma. Segundo a NBR 9050 item 8.7.3, a metragem de 90 centímetros possibilita a passagem de um cadeirante.

Já a metragem de $1,20 \mathrm{~m}$ possibilita a passagem de uma pessoa com cadeira de rodas e um pedestre, conforme a NBR 9050 item 4.3.1, com o objetivo de promover um espaço que facilite a mobilidade dos alunos ou servidores, sendo cadeirantes ou náo, cumprindo com os conceitos de acessibilidade (Figura 10). As medidas adotadas pelas pesquisadoras para a adequação do ambiente destinado para o acervo da biblioteca foram as mesmas elencadas pelos autores Coutinho e Silva (2012), como norteador

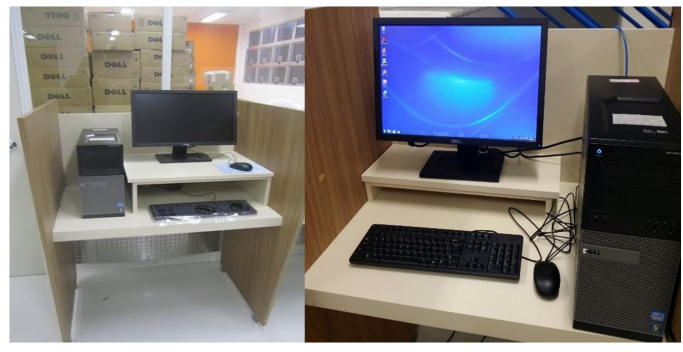

Figura 9. Bancada destinada aos computadores suporte para o monitor - antes e depois da adequação. Fonte: As autoras (2015).

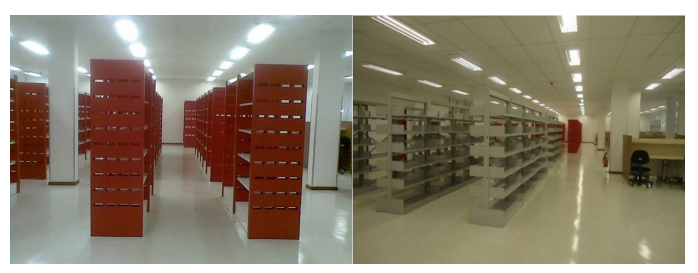

Figura 10. Layout das estantes do acervo com distância adequada. Fonte: As autoras (2015).

para a realização de uma análise das condições de acessibilidade em uma biblioteca universitária na cidade de João Pessoa-PB.

Há presença de pilares de sustentação entre as estantes, conforme mostra a Figura 10; para tal, foi utilizada a medida de 90 centímetros entre as estantes alocadas, para que não se impossibilite a passagem da cadeira de rodas. Portanto, mesmo com as barreiras físicas presentes no local, estas não irão interferir na acessibilidade de quem busca a biblioteca (Figura 10).

Para o remanejamento das estantes, a fim de cumprir as medidas estabelecidas pelas normas utilizadas, foram feitas demarcações no piso, com o auxílio de fita crepe, para que o Setor de Manutenção da universidade executasse o que foi proposto pelas pesquisadoras.

\subsection{Bancadas de estudo individual}

Em relação às bancadas, foram alocadas para um dos lados diferentes da planta baixa, para que, no outro lado, ficasse um espaço para estudo em grupo. Quanto às medidas entre as bancadas individuais de estudo, estabeleceu-se $1,30 \mathrm{~m}$, procurando possibilitar uma área de circulação acessível, respeitando a normatização da NBR 9050 item 4.3.1, que visa a deixar o espaço de $1,20 \mathrm{~m}$ a $1,50 \mathrm{~m}$ para passagem de um cadeirante e um pedestre (Figura 11). 


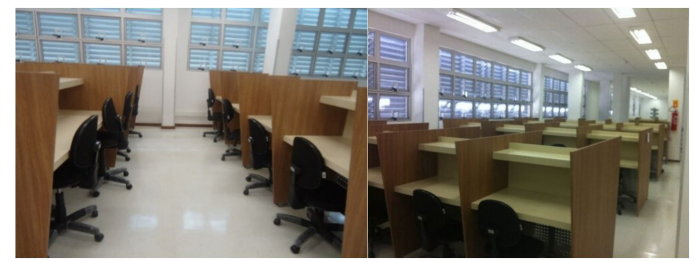

Figura 11. Distância entre as bancadas de estudo individual. Fonte: As autoras (2015).

\section{Conclusão}

A possibilidade de poder adequar o ambiente antes do seu funcionamento favorece um espaço laboral propício ao desenvolvimento das tarefas, à organização do trabalho e à manutenção da saúde dos usuários, bem como um ambiente acessível para os acadêmicos e a comunidade que usarão a biblioteca. As açóes foram realizadas com o propósito de prevenção e promoção da saúde dos usuários e servidores, garantindo, assim, melhores condiçóes de estudo e trabalho.

As intervençôes nesse ambiente foram apenas o início de um trabalho, que deve ser continuado e mantido depois da inauguração desta biblioteca. Este estudo teve, como limitação, a ausência de trabalhadores atuando no local, devido ao adiamento da inauguraçáo do campus em que a biblioteca se encontra. Esse fato náo permitiu a implementaçáo das adequaçóes pertinentes ao posto de trabalho dos servidores. Todavia, pretende-se dar continuidade ao estudo, assim que os servidores estejam alocados em seus postos de trabalho, para que os ganhos gerados pelas adequaçôes não sejam em vão.

Também foi possível compreender o papel do terapeuta ocupacional como consultor e articulador de uma equipe. Ressalta-se que este artigo teve como foco principal evidenciar as modificaçôes realizadas no layout da biblioteca, porém destaca-se que não adianta realizar alteraçóes no ambiente se a organizaçáo de trabalho não for salutar. Blattmann e Borges (1998) relatam que condiçóes de trabalho favoráveis possibilitam positivamente a realização das devidas tarefas. Capri, Bahia e Pinto (2012) corroboram tal posicionamento, relatando que trabalhadores e usuários, quando satisfeitos com o ambiente, podem produzir em melhores condiçôes, na medida em que trabalham de maneira mais adequada às suas necessidades. Contudo, espera-se que ambiente e organização de trabalho permaneçam equilibrados para o alcance do desempenho ocupacional satisfatório.

\section{Referências}

ABRAHÃO, J. et al. Introdução à ergonomia: da prática à teoria. São Paulo: Blucher, 2009.

ADEYEMI, A. O. ICT facilities: ergonomic effects on academic library staff. Library Philosophy and Practice, Lincoln, p. 1-5, 2010. Disponível em: <http://digitalcommons.unl.edu/>. Acesso em: 14 dez. 2015.

ASSOCIAÇÃO BRASILEIRA DE NORMAS TÉCNICAS - ABNT. NR 17: 1990: ergonomia. Rio de Janeiro, 1990. Disponível em: <http://portal.mte.gov.br/data/files/FF8080812BE914E6012BEFBAD7064803/nr_17. pdf $>$. Acesso em: 13 mar. 2015.

ASSOCIAÇÃO BRASILEIRA DE NORMAS TÉCNICAS - ABNT. NBR 9050: 2004: acessibilidade a edificaçóes, mobiliário, espaços e equipamentos urbanos. Rio de Janeiro, 2004. Disponível em: <http://pfdc.pgr.mpf. gov.br/atuacao-e-conteudos-de-apoio/legislacao/pessoa-deficiencia/norma-abnt-NBR-9050/view>. Acesso em: 28 abr. 2015.

BARRETO, T. L. M.; COUTINHO, I. J. Avaliação de acessibilidade da biblioteca pública do estado da Bahia: discussóes e reflexôes. Revista Baiana de Terapia Ocupacional, Salvador, v. 1, n. 1, p. 57-65, 2012.

BLATTMANN, U.; BORGES, I. Ergonomia em biblioteca: avaliação prática. Revista ABC: Biblioteconomia em Santa Catarina, Florianópolis, v. 3, n. 3, p. 45-62, 1998.

BRANDIMILLER, P. A. O corpo no trabalho: guia de conforto e saúde para quem trabalha em microcomputadores. São Paulo: Senac, 2002.

BRASIL. Ministério do Trabalho e Emprego. NR 17: ergonomia. Portaria MTPS no 3.751, de 23 de novembro de 1990. Diário Oficial [da] República Federativa do Brasil, Brasília, DF, 23 de nov. 1990. Disponível em: <http://portal.mte.gov.br/data/files/FF8080812BE914E6012BEFBAD7064803/nr_17.pdf>. Acesso em: 18 jun. 2013.

BLOCK, P. Consultoria, o desafio da liberdade. São Paulo: Makron Books, 1991.

CAMAROTTO, J. A.; SIMONELLI, A. P.; RODRIGUES, D. S. Ergonomia e Trabalho. In: SIMONELLI, A. P.; RODRIGUES, D. S. Saúde e trabalho em debate: velhas questôes, novas perspectivas. Brasília: Paralelo 15, 2013. p. 33-55

CAPRI, D.; BAHIA, E. M. S.; PINTO, A. L. Ergonomia: estudo de caso em biblioteca universitária. Revista Biblios, Brasília, n. 48, p. 42- 54, 2012.

CHANDRA, A. M. et al. Ergonomic issues in Academic Libraries in Kolkata, West Bengal: a pilot study. Library Philosophy and Practice, Lincoln, p. 1-8, 2009. Disponível em: <http://digitalcommons.unl.edu/cgi/viewcontent. cgi?article $=1288 \&$ context $=$ libphilprac $>$. Acesso em: 20 dez. 2015.

COUTINHO, J. F. P.; SILVA, A. L. A. Analisando as condiçôes de acessibilidade para usuários com deficiência física numa biblioteca universitária em João Pessoa. 
Biblionline, João Pessoa, v. 8, p. 3-17, 2012. Edição especial.

COSTA, K. S. B. D. Organização de bibliotecas: espaço físico. [S. 1.]: Senac/Sics, 2008. Disponível em: <http://www.dn.senac.br/cedoc/ Organiza\%C3\%A7\%C3\%A3o\%20de\%20bibliotecas. doc>. Acesso em: 1 maio 2015.

DAVOK, D. F.; PEREIRA, C. P. C.; ORDOVÁS, G. B. Estudo do layout da biblioteca pública de Santa Catarina. Revista $A C B$, Florianópolis, v. 16, n. 1, p. 341-357, 2011.

FLECK, L. K. Estudo das condiçôes de trabalho em bibliotecas acadêmicas de uma universidade pública federal. 2004. 153 f. Dissertação (Mestrado Profissionalizante em Engenharia) - Universidade Federal do Rio Grande do Sul, Porto Alegre, 2004.

FONTES, A. R. M. et al. Projeto de guichê de atendimento contextualizado pela Análise Ergonômica de Trabalho. Revista GEPROS: Gestão da Produção, Operaçōes e Sistemas, São Paulo, n. 1, p. 111-124, 2006.

FUNDAÇÃO BIBLIOTECA NACIONAL. Biblioteca Pública: princípios e diretrizes. Rio de Janeiro: Fundação Biblioteca Nacional, 2000.

GUÉRIN, F. et al. Compreender o trabalho para transformá-lo: a prática da ergonomia. Sáo Paulo: Blucher, 2001.

MACIEL, M. H.; MARZIALE, M. H. P. Problemas posturais $\mathrm{X}$ mobiliários: uma investigação ergonômica junto aos usuários de microcomputadores de uma escola de enfermagem. Revista da Escola de Enfermagem da USP, São Paulo, v. 31, n. 3, p. 368-386, 1997.

MOURA, C. F. et al. Análise ergonômica de ambientes de informática: os usuários de computadores e a importância da prevenção da LER/DORT. In: WORKSHOP DE ANÁLISE ERGONÔMICA DO TRABALHO, 2., 2005, Viçosa. Anais...Viçosa, 2005. p. 35-42.

PICOLli, G. S.; CARNEIRO, J. C. D.; BRASIL, P. C. G. A importância da integraçáo do layout ao espaço. Revista Virtual de Ergonomia: Ensaios de Ergonomia, Flo- rianópolis, 2000. Disponível em: <http://www.eps.ufsc. br/ergon/revista/artigos/artigo_layout-.pdf >. Acesso em: 9 jun. 2012.

PIMENTEL, G.; BERNARDES, L.; SANTANA, M. Biblioteca escolar. Brasília: Universidade Federal de Brasília, 2007. Disponível em: <http://portal.mec.gov.br/ seb/arquivos/pdf/profunc/biblio_esc.pdf $>$. Acesso em: 9 maio 2015.

PUPO, D. T.; MELO, A. M.; FERRÉS, S. P. Acessibilidade: discurso e prática no cotidiano das bibliotecas. São Paulo: UNICAMP/Biblioteconomia, 2008.

RIO, R. P.; PIRES, L. Ergonomia: fundamentos da prática ergonômica. São Paulo: LTr, 2001.

RODRIGUES, D. S.; SIMONELLI, A. P.; LIMA, J. A atuação da Terapia Ocupacional na saúde do trabalhador. In: SIMONELLI, A. P.; RODRIGUES, D. S. Saúde $e$ Trabalho em Debate: velhas questôes, novas perspectivas. Brasília: Paralelo 15, 2013. p. 225-239.

ROONEY, H. Ergonomics in academic libraries. Library Management, Canadá, v. 15, n. 1, p. 26-35, 1994.

SILVA, A. A. A ergonomia e o ambiente de trabalho: reflexões sobre as contribuições ergonômicas em bibliotecas. Informação \& Sociedade: Estudo, João Pessoa, v. 18, n. 3, p. 73-81, 2008.

SOBRAL, M. J. G. C.; LIMA, P. Análise e intervenção ergonômica em postos de trabalho com computadores: a percepção dos trabalhadores. 2014. 88 f. Dissertação (Mestrado em Segurança e Higiene do Trabalho) - Instituto Politécnico de Setúbal, Portugal, 2014.

WATANABE, M.; GONÇALVES, R. M. A. Relações Conceituais entre Terapia Ocupacional e Ergonomia. In: LANCMAN, S. Saúde, Trabalho e Terapia Ocupacional. São Paulo: Roca, 2004. p. 19-70.

WATANABE, M.; NICOLAU, S. M. A Terapia Ocupacional na interface da saúde e do trabalho. In: CARLO, M. M. R. P.; BARTALOTTI C. C. Terapia Ocupacional no Brasil: fundamentos e perspectivas. São Paulo: Plexus, 2001. p. 155-169.

\section{Contribuição dos Autores}

Iranise Moro Pereira Jorge foi coordenadora deste projeto. Aline Andreia Klein, Aline dos Santos Ávila e Ellen Geraldine Sakowicz participaram de todas as etapas. Todos os autores aprovaram a versão final do texto.

\section{Notas}

${ }^{1}$ O presente artigo faz parte de pesquisa e intervenção. Parte do seu conteúdo foi apresentada no VI Congresso Paranaense de Terapia Ocupacional.

${ }^{2}$ Projeto aprovado pelo Comitê de Ética em Pesquisa da Universidade Federal do Paraná, com o número de protocolo CAAE 27673914.2.0000.0102. 